\title{
Code of behaviour at sea: women seafarers' shipboard identity management
}

\author{
Momoko Kitada
}

Received: 11 September 2012 / Accepted: 4 April 2013 /Published online: 23 April 2013

(C) World Maritime University 2013

\begin{abstract}
The employment of women on cargo ships, particularly at officer's level, is paid more attention in order to supplement the shortage of qualified officers. However, seafaring jobs are still overwhelmingly dominated by men, and there seems to be gender-related challenges for women in such work environment. Women seafarers in this research are those who work in the ship operational sections on cargo ships as deck officers, engineers or radio officers. A total of 36 female and 8 male seafarers from eight different countries participated in the project and shared their experiences of working on board ships. The research revealed that the occupational culture of seafaring often reflects masculine norms and values which could affect women seafarers' behaviour and attitudes. This paper further explores how women manage such situations on board by utilising various strategies in order to avoid gender-related problems. This study identifies a typical pattern of women seafarers' identity management and creates a model of women's strategic shifting patterns over time.
\end{abstract}

Keywords Women seafarers · Occupational culture - Gender identity management · Masculinity $\cdot$ Femininity

\section{Introduction}

Seafaring is one of the traditionally male-dominated occupations for a long time. A number of documents on the basic assumption that seafarers are men were described, and the expression of 'he', 'his' and 'him' can be observed in the literature. In fact, the word 'seafarers' is gender-neutral and has been replaced by the masculine forms, such as 'seaman'. However, there are still some arguments about which word is appropriate. In the 294th session of the International Labour Organization (ILO) in 2005 , an official proposed the use of the word 'seafarer' instead of 'seaman', drawing

\footnotetext{
M. Kitada $(\bowtie)$

World Maritime University, Citadellsvägen 29, P.O. Box 500, 20124 Malmö, Sweden

e-mail: mk@wmu.se
} 
attention to the fact that gender-neutral language cannot yet be taken for granted within the industry and the maritime community:

Mr. ... in the resolution concerning the ILO minimum wage for able seamen ... also suggested the use of the word "seafarer" instead of "seaman". (ILO 2005, p. 10)

This is just one example of many that illustrates how the shipping industry is still male-dominated and how the recognition of women seafarers is often neglected even in such official sites. In 1992, the International Maritime Organization (IMO) made an estimation of women's representation in seafaring, just 1 to $2 \%$ of the world's 1.25 million seafarers (Belcher et al. 2003, p. 9). The more recent study (Sulpice 2011) analyses the statistics of women seafarers in six European countries (Bulgaria, Germany, Lithuania, Norway, Sweden and UK) and concludes that there has not been much improvement in increasing the number of female seafarers. A similar concern was addressed in the case of US merchant marines (Brickman 2012). Nevertheless, the presence of women seafarers has been emphasised, and for example, 10 out of 12 issues of the shipping newspaper Telegraph published in 2012 included a picture of a female cadet or officer in their articles (Nautilus 2012).

Despite the overwhelming male domination in the seafaring workforce, the employment of women in ship operational sections has recently drawn more attention (Belcher et al. 2003, pp. 6-7). The two main reasons for this are market factors relating to a shortage of ship officers and factors relating to their strategic promotion within the labour market. The Baltic and International Maritime Council (BIMCO) and the International Shipping Federation (ISF) reported that there would be a shortage of 13,000 officers worldwide, and this was expected to be either maintained or worse in 2015 (BIMCO/ISF 2010). For the improvement of this situation, IMO launched the 'Go to Sea' campaign in 2008 to set a target on young people to enter seafaring careers. It aims for several goals, including the task of 'urging more women to consider working as seafarers' (DeSimone 2010).

Women working in male-dominated professions are well documented, for example, firefighters (Yoder and Aniakudo 1995, 1996), army officers (Pettersson et al. 2008), police (Holdaway and Parker 1998), and the navy (Newell et al. 1995). There is also evidence that female workers in male-dominated jobs tend to conduct gender management in order to fit into their environment (see, for example, Cassell and Walsh 1993). In the case of women seafarers, do they also strategically manage their gender identities when working on ships? If so, how do they change their behaviour and attitudes? How do they feel about it? This paper explores the ways in which women seafarers manage their gender identities in relation to their male colleagues while at sea.

\section{The setting for the study}

This research looks into women in the context of the extremely male-dominated work environment of ships where, if there is, only one female can be found and works with 17 or 18 male crew members for several months. Hence, this paper only considers those women working as a deck officer, engineer or radio officer on merchant cargo ships. In other words, women seafarers on other types of vessels, such as cruise ships, 
ferries, yachts, fishing boats and naval (non-merchant) ships are excluded in this research because these vessels often accommodate different working conditions. For example, cruise ships and ferries are likely to have many female workers, mostly in hotel and catering sections. Yachts, fishing vessels and naval ships are not the same as merchant cargo ships in terms of their purposes of operation as well as their organisational structures. Therefore, it is inadequate to include women sailors on other types of vessels as we cannot assume that they experience the same culture as women seafarers in this study do.

\section{Methods}

\subsection{Procedure and participants}

This research was designed to have two phases: the first phase was to investigate how both female and male seafarers perceive the occupational culture of seafaring, and the second was to ask female seafarers about their identity management if they did. In response to a number of debates about feminist epistemology (Maynard and Purvis 1994), this research included male voices as well as female in the first phase in order to capture a better understanding of the seafaring culture that both men and women experienced.

The primary data collection method relied on individual face-to-face interviews. Other methods, such as focus groups and participant observation, were simply inapplicable due to the nature of seafaring jobs. Focus groups require participants to gather in one place at once; however, it was not easy to find a group of women seafarers all together in a particular location. Participant observation can be disturbing if the researcher chases a female seafarer on board. Although individual face-to-face interviews were planned, other methods were also utilised because of the feasibility of the study, and it will be discussed in the next section.

The small population of women seafarers made it difficult to contact them, while finding male seafarers for interviews was relatively easy. The recruitment of women seafarers began with identifying the contact persons who might know how to find women seafarers in some countries, through the network of the Seafarers International Research Centre where I was undertaking my research project. Snowball sampling was also utilised in this study, and the appointments for interviews were made by e-mail. The initial e-mails briefly explained the aims and objectives of the research, what participation would involve and guaranteeing confidentiality and anonymity. The information leaflet was attached for further details of the research. Hence, a positive reply to a request for the interview was taken as informed consent. However, a written form of participant's consent prior to the interview was also obtained.

This project finally attracted 44 participants (36 females and 8 males) from eight different countries: Sweden (F, 12; M, 1), Germany (F, 11; M, 2), Portugal (F, 9; M, 1), Poland (F, 1), Ghana (F, 1), UK (M, 1), Netherlands (M, 1), and Japan (F, 2; M, 2). The participants were diverse in terms of age, rank and seafaring experience. The youngest participant was 19 while the oldest was 57 years old. There were people from third/fourth mates to captain/chief engineer. Their sea-going experiences were between 6 months and 29 years. 


\subsection{Data collection and analysis}

The majority of participants (F, 30; M, 8) were individually interviewed face-to-face as planned. However, other data collection methods, for example, group interview, telephone interview and e-mail interview, were also utilised due to the feasibility of data collection as well as the requests from the participants. For example, a group interview was chosen once upon a request from four women seafarers who were all friends gathered at once. The group interview saved time and allowed them to stay relaxed without worrying about the train time. One telephone interview was carried out with a participant who was introduced to me only after the fieldwork trip to her country had taken place. An e-mail interview was conducted at the suggestion of a busy, yet enthusiastic woman seafarer as it was her only possible way to participate in the research. The application of different methods was unavoidable, and the research showed that the richest interview data were in fact from individual face-to-face interviews as primarily designed.

The face-to-face interviews were conducted in public places like cafés, restaurants, offices, hotels or ships, except for two cases that took place in private sites that were the participants' own houses. These interviews began with some casual conversation to establish a good rapport. I focused on their narrative stories and experiences and let them talk rather than guiding the interview with prescribed questions. Each interview lasted for 1.5 or $2 \mathrm{~h}$ on average, while the longest one was up to $4 \mathrm{~h}$. During the interviews, an audio digital recorder was used with the participants' permission.

As part of the analysis, the interview data were transcribed into written texts (Kvale 1996, p. 88). Transcribed texts were thereafter coded and analysed using the qualitative research software NVivo. To protect participants' confidentiality, their real names were concealed anywhere, and all the individuals were assigned a pseudonym which will be stated along with the quoted texts in the following sections.

\section{Results and discussion}

Despite the wide variety of the participants' backgrounds, including their nationalities and age, all male and female interviewees agreed that the onboard culture reflects masculine values and norms both on and off duties. A German male captain, Martin, talked about the shipboard culture in general as:

Masculinity (...) definitely the job and the tone onboard is, now I always talking about cargo ships (...) but definitely on cargo ships, it's masculinity. (Martin, age 44, German, captain)

A Portuguese female radio officer, Rose, explained that she joined most off-duty activities on board except for a particular activity associated with male interests, for example:

The only thing I did not enjoy was when they were watching erotic or pornographic film. No, I don't. In public places. I won't come to that. (Rose, age 45, Portuguese, radio officer) 
As both male and female seafarers highlighted, masculine norms and values are dominant in the seafaring culture, and being a woman often means being different from the rest of the crew. It would be problematic for not only female but even male seafarers if they fail to act as part of the working team on board because seafarers need to be 'tuning in to' each other as a Swedish male seafarer, Fredrik, described:

Seafarers are in high degree of capability of tuning than the average shore people. (Fredrik, age 36, Swedish, senior deck officer)

The occupational culture of seafaring presents its own rules and regulations; therefore, seafarers must shape themselves to a certain form of personalities and adjust and standardise to meet the requirements within the occupational culture. Most interviewees answered that there are certain rules and taboos on board ships, as the metaphor 'code of behaviour' in the title of this paper infers. Hence, it seems to be critical particularly for women seafarers to fit into such a male-oriented environment in order to be accepted as part of the crew while at sea. The research revealed that women seafarers tended to strategically modify their behaviour and attitudes, as other literature refers to gender management of female workers in male-dominated occupations. Despite most studies stating that female workers in such working environment behave in either masculine or feminine manners to deal with their male counterparts, this research examined the patterns of women seafarers' identity management while at sea.

In analysing the transcribed interview data, four identity management groups emerged: 'negotiators', 'constructors', 'maintainers' and 'reproducers'. These typologies were created by employing the idea of ideal types (Weber 1949) in order to understand women seafarers' identity management. The research identified the tendency that when women seafarers first went to sea, many struggled with their gender as being women which was overly focused. As a result, they felt insecure and uncomfortable in relation to their male colleagues on board ships. They realised a need to negotiate their gender identities to fit into the male-dominated environment (negotiators). Some women of my sample, however, felt a need to further develop their identity management by 'acquiring' a more appropriate identity to be accepted as a crew member (constructors). Eventually, the majority of women seafarers went on to maintain themselves without being affected as much and felt easy and comfortable with their identity management (maintainers). The study also found that some active-thinking women seemed to become what I have termed reproducers by redefining themselves, and described a feeling of freedom and confidence in relation to their understanding of who they were. Hence, the ways of women seafarers' identity management are rich and diverse. Each identity management group includes a few distinguished strategies which women seafarers utilised while at sea (see Table 1).

\subsection{Hiding feminine signs — strategies of negotiators}

Women seafarers in the early stage of their careers tend to learn a need for negotiating their gender identities to fit into the male-dominated workplace, as a Portuguese captain, Vidonia, stated 'I definitely had to learn to be more discrete.' The common negotiator 
Table 1 Woman seafarers' ideal typical identity management strategies

\begin{tabular}{|c|c|c|}
\hline Ideal typical identity group & Emotion/feeling & Identity strategy while at sea \\
\hline Negotiators & $\begin{array}{l}\text { Uneasy, difficult, anxious, stressful, } \\
\text { misunderstood, uncomfortable, } \\
\text { struggling, conflicting, insecure, } \\
\text { inappropriate }\end{array}$ & $\begin{array}{l}\text { The obscurers of femininity } \\
\text { The reinforcers of masculinity }\end{array}$ \\
\hline Constructors & $\begin{array}{l}\text { Open to a new view and perspective, } \\
\text { accepted, appropriate, fit well to } \\
\text { their gender roles }\end{array}$ & $\begin{array}{l}\text { The acquirers of femininity } \\
\text { The acquirers of masculinity }\end{array}$ \\
\hline Maintainers & $\begin{array}{l}\text { Happy, easy, comfortable, balanced, } \\
\text { table }\end{array}$ & $\begin{array}{l}\text { The retrievers } \\
\text { The disguisers } \\
\text { The never-changers }\end{array}$ \\
\hline Reproducers & $\begin{array}{l}\text { Free, secure, confident, achieved, } \\
\text { reborn, liberated }\end{array}$ & $\begin{array}{l}\text { The alleviators } \\
\text { The manipulators of femininity } \\
\text { The manipulators of masculinity } \\
\text { The neuters }\end{array}$ \\
\hline
\end{tabular}

strategies on board include 'the obscurers of femininity' and 'the reinforcers of masculinity'.

Women seafarers in my sample commonly felt uncomfortable when they were seen as 'women' rather than 'people' or 'seafarers' by their male colleagues on board ships. Out of 36 female seafarers, 25 attempted to look less feminine in their appearance and/or behaviour (the obscurers of femininity). Some chose their clothes in terms of being not too sexy when they packed for the voyage because it might be inappropriate in front of men who have been away from family and lovers for a long time and do not often see women on board their ships. A German deck trainee, Cindy, explained:

I know a lot of men are alone on board and there is no women. Yeah, they have desires, sure. If there is a woman with no sleeves and yeah, maybe tight trousers, they are looking, maybe try to touch her. It's clear, I think. So I try to, when I made my luggage, "Ok, this...? NO, it's too sexy." (laugh) "Hmm, this... also sexy?" Yeah. A bit more cover and a bit more wider, not too tight. (Cindy, age 23, German, deck officer trainee)

Women utilising the strategy of the obscurers of femininity wished to avoid being viewed as sexual beings and wanted instead to be accepted as colleagues. In addition, hiding feminine signs was extended to the behaviour of expressing emotions and feelings. Such acts were considered as feminine and unprofessional, thus problematic on board. For example, a German deck trainee, Marina, felt that she had to 'cut off' the display of her emotions and feelings while at sea because these attributes were considered feminine.

"Oh yes, female. Going to show emotions and feelings. Oh, always crying.", or I don't know, yeah it was. No, when I am on board, I am not talking about my emotions or feelings or whatever. (Marina, age 22, German, deck officer trainee) 
Women using the obscurers of femininity strategy were concerned about how they were regarded by their male colleagues. Masculine norms and values are so dominant in the occupational culture of seafaring that even a subtle sign of femininity can be taken as a marker of difference at sea. Indeed, the obscurers of femininity strategy offered a good entry to work in such a male-dominated environment; however, some women found that it was not sufficient enough to convince their male colleagues to accept them as part of the crew. In fact, some women attempted to make a further adjustment to their identities and adopted a different type of negotiator strategy which I have termed the reinforcers of masculinity.

The strategy of the reinforcers of masculinity involved women seafarers forcing themselves to behave like men, and this can be understood as one step further compared to the less feminine behaviour of the obscurers of femininity. Out of 36 women in my sample, 8 utilised this strategy while at sea. However, these women did not feel happy about the strategy and reluctantly negotiated their identities by reinforcing masculinity. For example, a German deck trainee, Inge, told me that she wanted to be as strong as men yet did not wish to be like men and simply desired to be a strong woman.

Uh, I want to be strong. I want to be like the others. I don't want to be a "GIRL", you know. ...I try to be like a strong woman. (Inge, age 25, German, deck officer trainee)

At the level of negotiators, women seafarers have not yet constructed a masculine identity. Since these two negotiator strategies (the obscurers of femininity and the reinforcers of masculinity) provide only temporary solutions for them to escape from gender-related problems on board ships, some women sought a more tangible solution to avoid trouble at sea and felt a need to construct a masculine identity.

\subsection{Crafting selves - strategies of constructors}

While the negotiator strategies offer temporary solutions, the constructor strategies focus on a more effective way of solving gender-related problems by acquiring a new gender identity. The most popular constructor strategy among women seafarers was to create a masculine type of identity (the acquirers of masculinity), and 21 out of 36 women in my sample utilised this strategy. Women using the acquirers of masculinity strategy tended to appreciate being 'a man' because they felt that their behaviour is 'appropriate' on board by acquiring a masculine type of identity. Indeed, such newly created masculine identity seemed to perfectly integrate into the occupational culture of seafaring. For example, a Swedish engineer, Sue, adopted a masculine style of behaviour while at sea and copied her male colleagues' roughness and swore more than men did.

I have been more macho than many men actually, because of course I become sort of a copy cat. I copy their behaviour, and if they are rude, I am a bit ruder. If they swear, I can swear too. Maybe a little bit more than they can. So I think I adopt the male behaviour. (Sue, age 45, Swedish, junior engineer)

Women seafarers using the acquirers of masculinity strategy often crucially desire to be accepted as part of the crew. They utilised a strategy of totally denying and 
obliterating their femininity, which allowed them to join a male group, and it was often successful. As a result, they found that it was appropriate to be masculine on board. On the contrary, only some women (5 out of 36 ) experienced acquiring a feminine type of identity while at sea (the acquirers of femininity).

Unlike the construction of a masculine identity, acquiring a feminine identity on board seemed to have no critical purpose yet rather reflected an awareness of femininity which some women displayed by differentiating themselves from their male colleagues. Women seafarers using the acquirers of femininity strategy tended to discover new feminine norms by themselves and enjoy being feminine at sea. For instance, some women intentionally dressed in a feminine outfit during their free time on board and found it comfortable when their male colleagues made compliments about their femininity. A Polish deck officer, Karolina, explains:

One hour before, I was quite dirty deck officer. And after one hour, I changed the new dress from a boutique in Indonesia, for instance. So I was looking like a butterfly. Of course at that time, my colleagues opened their eyes, 'Oh you are so beautiful.' and sometimes, 'Ah!' I was very happy. (...) finally of course I develop my female image. Because when I finished my study and I started my work, it didn't develop my female identity or something. So I developed in time of my job onboard the vessel. (Karolina, age 52, Polish, senior deck officer)

Some women seafarers talked about their own definitions of femininity during the interviews; thus, the definition of 'feminine' seems to be diverse. Seafaring experience tends to provide women with an opportunity to be open-minded and to develop their own version of gender identities.

\subsection{Keeping selves — strategies of maintainers}

While it was important for negotiators and constructors to find a solution to genderrelated problems aboard ships, maintainers seem to engage rather calmly and mildly in the management of their identities. Indeed, maintainers attempt to relieve their feelings and emotions from their imbalanced state of mind. There are three maintainer strategies: 'the retrievers', 'the disguisers' and 'the never-changers'.

Women using the retriever strategy adjust their lack of feminine identities while at sea, and half of the women in my sample (18/36) utilised this strategy while at sea. Some women seafarers explained how they were fed up with wearing 'boring' male clothes, such as overalls and shorts, all the time on board and missed 'dressing up' like a girl. These women dressed up and arranged their hair for special occasions like Christmas, barbeque parties or Sundays (in Christian culture like Portuguese ships) (the retrievers). A Swedish engineer, Sally, described how she wore feminine clothes and make-up on Christmas day on the vessel. When I interviewed her on the ship, she was between her duties and wearing her working clothes. She stated:

I am just a kind of girl. I like a man's profession like this one. But me, myself, I dress very much like a girl. Not as a man. I don't try to dress like a man. ... this Christmas, we had a Christmas table where we all ate...things like that. Then I wear a lot of feminine clothes. More make-up and kind of stuff. Right now, I am 
at work. I wear my working clothes and I don't wear make-up and I don't care hair styles and all like that. I even didn't brush hair this morning. So I don't care about how I look at work. (Sally, age 25, Swedish, junior engineer)

Having few opportunities to dress themselves up while at sea often made them bored in their daily shipboard lives which could last for several months. Some women seafarers became creative; for example, a Japanese engineer, Naomi, played with colours as a retriever strategy to discreetly express her feminine quality while on board and said:

I often express my little bit of resistance to this masculine culture. I choose a pair of sport shoes with 'red' lines. T-shirts become sweaty inside my boiler suits so I don't care much. My female colleague is using a 'red' hair band to tie up her hair. My wrist watch is 'pink'. Well, my diary is 'red' again. (Naomi, age 25, Japanese, junior engineer)

Naomi used the word 'resistance', and this explains that being feminine in such a male-dominated environment can be seen as a sign of women's persistence to not totally yield their own styles. Similar comments were also made by a Portuguese seafarer who had three different colours of slippers to match the colour of her T-shirt of the day while at sea.

While the retriever strategy tended to be utilised while off duty, another type of maintainer strategy, the disguisers, can be used whenever and wherever women seafarers want to use it. Out of 36 women in my sample, 13 appeared to apply this strategy. Women using the disguiser strategy seem to mask their true selves, including their femininity, tactically and elaborately in front of their male colleagues in order to maintain their identities. They do not express their feelings openly and keep their true selves deep inside. A Portuguese captain, Vidonia, explained:

As the years went by, I started socialising less and less, I showed less and less of myself and my feelings, the distance between me and people became bigger and bigger and I became more and more of a loner ... For the rest of the time, I felt I was just a "one of them" and even when I dressed up with the stuff I manufactured, it was more like a disguise than the true me! (Vidonia, age 51, Portuguese, captain)

Women using the disguiser strategy hid their feelings and emotions at back of their minds. This can be seen as a self-protection after a long period of working in the male-dominated workplace. Among the maintainer strategies, there were also a few women seafarers who did not change themselves and kept their original identities while at sea. These women are categorised as using the never-changer strategy because they maintained who they are.

The extreme version of the maintainer strategy is called the never-changers, and women who use this strategy often appeared to be tomboyish and not interested in feminine habits (e.g. make-up, wearing skirts or high heels). Some seemed to be even regarded as male rather than female by both men and women because of their 'fuzzy' gender identity. Although Fig. 1 shows that 28 women in my sample utilised the 


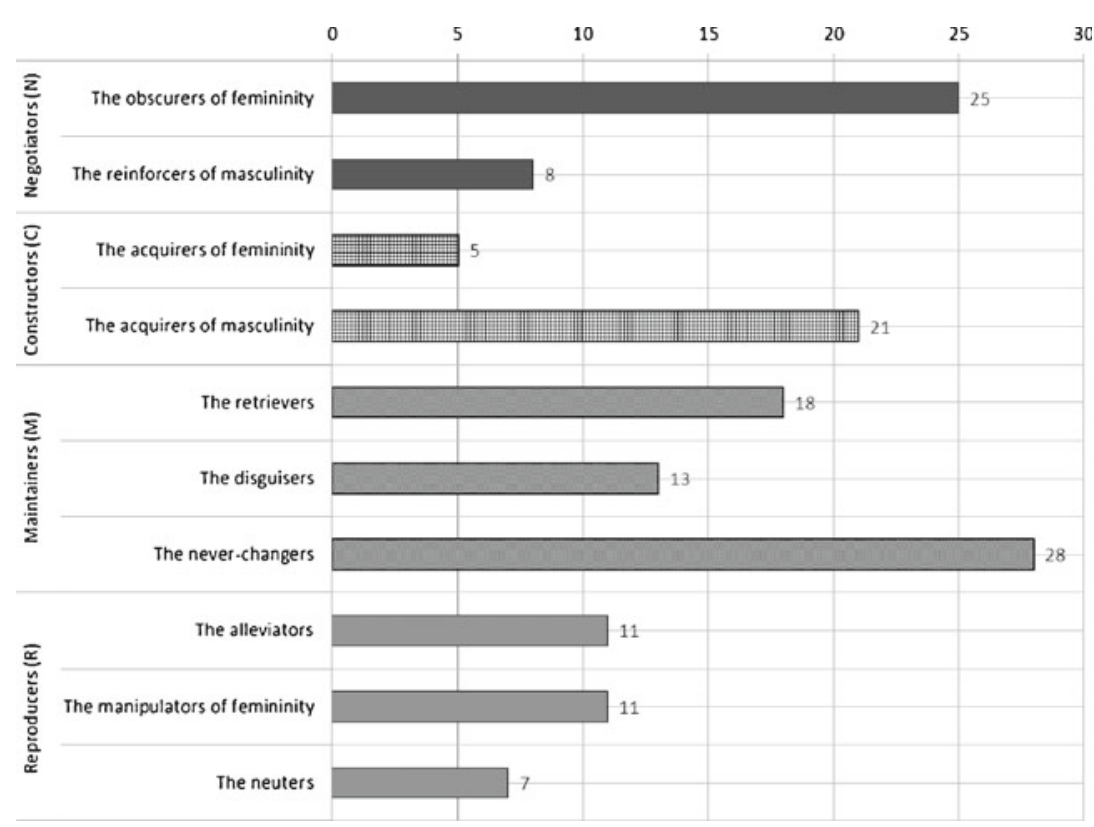

Fig. 1 The number of women who experienced using the strategy while at sea

never-changer strategy while at sea, the majority of them said that they did not change themselves at some point of their seafaring careers. However, they actually changed their behaviours and attitudes by utilising other strategies at other times. Hence, there were only two obvious cases of the never-changers in my sample who purely kept their ways while at sea. Despite their male-like appearance, women using the neverchanger strategy seemed to regard swearing and roughness as barbarous, uncivil and not acceptable to them. A Portuguese radio officer, Rose, explained:

See one of the officers, without T-shirt, [wore] no-sleeves T-shirt like that. I think "Oh dear ... it is too spoiling", because I was on my white shirt and white trousers, and he was in shorts with no shoes, [but just] sandals and T-shirt without sleeves. I think it's amazing, and the steward was serving us everything. I think this is not a good example. For me, that is the question of educational problems. Not exactly by knowledge, he attended the same school as I did. (Rose, age 45, Portuguese, radio officer)

Women using the never-changer strategy tended to be strong and honest about who they are. These women seemed to be less influenced by gender problems on board compared to negotiators and constructors.

\subsection{Releasing gender-related tensions — strategies of reproducers}

Of the four identity management groups, reproducers tended to engage in a relatively long and in-depth process of women seafarers' identity management in search for their 'authenticity'. Their feeling of incompleteness or unhappiness about their 
gender identity management let them try to redefine themselves. The reproducer strategies utilised on board ships include 'the alleviators', 'the manipulators of femininity' and 'the neuters'.

Firstly, the strategy of the alleviators can release an excess degree of masculinity from women seafarers by obtaining an alternative safeguard, for example, promotion, age, marriage and religion. Two captains from Germany and Ghana explained how they felt secure in their position when they were promoted to a higher rank within the ship's hierarchy because their job title as a ship master authorised their capability at work.

When I was still an apprentice and a cadet, it was worse. So higher you get, it gets less. Especially the chief mate, you must know something, otherwise you are not a chief mate. And so you came on board and "Oh, a female chief mate, something new, ok.” They don't watch you so much. (Doris, age 43, German, captain)

When I got my Master's (license) and became a Captain, I was a bit more relaxed. A bit more relaxed. So easier for me. (Sisi, age 52, Ghanaian, captain)

As they illustrated, women using the alleviator strategy tended to see the effect of promotion to a higher rank because they could abandon the 'shell' that they had created for their identity management in the past. Some women using the alleviator strategy reported that age can be another important element for women seafarers to feel secure. Becoming a more mature woman by age seems to decrease their sexual appeal and increase the security of their gender identities aboard ships. Other women using the alleviator strategy who married a male seafarer tended to receive respect from other male colleagues because of 'belonging' to a particular male seafarer. This phenomenon can be viewed as part of the occupational culture of seafaring, that seafarers would never touch others' 'belongings'. A bonus protection resulting from being a wife of a male seafarer seemed to release the pressure of identity management. Another example of the alleviator strategy was a religious woman seafarer and how her connection to God became an alternative protection for her on board ships. She described that her relationship with God made her comfortable and courageous when talking to men without worrying about her gender identities. Women using the alleviator strategy, by attaining an alternative safeguard (i.e. promotion, age, marriage, religion), could remove their mask of masculinity. Out of 36 women in my sample, 11 utilised this strategy while at sea.

Another strategy of the reproducer group, the neuters tended to abandon the concept of gender so that they can release themselves from the spell of gender while at sea. Gender does not seem to matter to them because they define themselves 'a person', neither a man nor a woman. There were seven examples of women in my sample who applied this strategy. A German deck trainee, Vicki, stated that she is a person where the idea of gender is not predominant. Hence, her self-identification became more gender-neutral.

I found the identification for me, and I identify myself as a person, Vicki, with my whole past. It is not just like a student or a woman, or ... I am a person! (Vicki, age 20, German, deck officer trainee) 
Being a woman often appears to be disadvantageous and problematic in the occupational culture of seafaring which tends to reflect masculine norms and values. However, the strategy of the manipulators of femininity may intentionally create an imaginative patriarchal relationship between women seafarers and their male colleagues by keeping a low profile. This strategy would help save male seafarers' face and hide the idea that women can be smarter than men. A Swedish captain, Emma, was wise enough to use a trick to control male crew on the vessel. For example, when one of her male colleagues did not like to be 'ordered' what to do, Emma elaborately suggested that he should do a time-rich job because she wanted to make him suggest a more urgent job which she actually wanted him to do. She explained that she used a feminine style of communication as a strategy when giving an order to her male colleague.

Instead I am telling him today we should do this, he said to himself. But I had learned that after a while. I think it's easier maybe this female thinking, you can think around. ... I know that he is straight in communication, so I turned it another way. But he doesn't understand me, because I am doing a woman's thinking. ... I started the other way. Talking about something we should do later, maybe. But then he is smart. "Now we have to do this today, because this is there." That's exactly what you should do! (laugh) (Emma, age 39, Swedish, captain)

The strategy of the manipulators of femininity seemed complex, so it could be difficult for men to understand women's covert messages and the fact that women had won the game. All the users of the strategy of the manipulators of femininity strategically found out the best feminine gender role for them in such a maledominated workplace and knew how to apply their femininity to control shipboard situations in relation to their male colleagues.

\subsection{A choice of identity management strategies}

The interview data revealed that 36 women seafarers in my sample utilised various identity management strategies while at sea. Fig. 1 shows the number of women seafarers who experienced each identity management strategy. The most common strategy was the never-changers (28 out of 36); however, the majority of women who utilised this strategy actually engaged in managing their identities by using negotiator or constructor strategies. Many women seafarers stated that they did not change themselves on board although they struggled with gender-related problems other times and modified their behaviour and attitudes as negotiators and constructors. The purely never-changed women seafarers while at sea were, as I explained in the earlier section, only two in my sample.

Apart from the remark of the never-changer strategy, Fig. 1 shows that some strategies were more popularly used by women than others, such as the obscurers of femininity and the acquirers of masculinity. It explains that their feminine identity was problematic on board, and they tried to adjust their femininity by using these identity management strategies. Another general tendency of women's identity management is that maintainer strategies were utilised more often, and reproducer strategies were utilised less in comparison. The research found that maintainer strategies were the 
most stable and balanced state of mind and play a role of hub station to pass through for many women seafarers. Reproducer strategies were, on the other hand, were difficult to reach; hence, they were experienced the least.

\subsection{Identity management model while at sea}

Female seafarers talked about their shipboard identity management in various ways during the interviews. They often began by describing their pre-seafaring identity management strategies. However, some started their narratives from the time they first went to sea and spoke about how they saw their femininity as problematic and attempted to fit into the shipboard environment (negotiators). In other words, the starting points of women's narratives about their identity management varied. In addition, many women seafarers started with the same identity management strategies. However, the ways in which they changed their strategies and how they ended up with a particular identity management strategy were diverse. Nevertheless, several tendencies of women seafarers' identity management emerged through this research, and I attempted to identify the patterns of their identity management.

The research identified a typical pattern of women seafarers' identity management they experienced while at sea. Most women attempted to change themselves to fit into their environment (negotiators) and then moved on to acquire a new identity in order to adjust to a more appropriate gender identity (constructors). Beyond this process, some women changed again and sought to retain their original identities as much as possible (maintainers), and at last, some women went on to enjoy the production of a redefined identity (reproducers). Based on observations of identity management, Fig. 2 shows a basic model of vectoral shifts of women seafarers' identity management between four identity management groups.

Every shift between identity management groups, which women seafarers in my sample experienced, was extracted from the accounts given at interview. For instance, the shifting of negotiators $\rightarrow$ constructors $\rightarrow$ maintainers $(\mathrm{N} \rightarrow \mathrm{C} \rightarrow \mathrm{M})$ was interpreted to be a combination of two different shifts of $\mathrm{N} \rightarrow \mathrm{C}$ and $\mathrm{C} \rightarrow \mathrm{M}$. After such vectoral information was extracted from the interview data, I investigated how many times each shift was experienced in order to examine which shifts were most prevalent. I categorised a strong relationship as over $30 \%$, a medium relationship as 20-30\% of total shifts and a weak relationship as below $20 \%$ of total shifts. The strong relationships

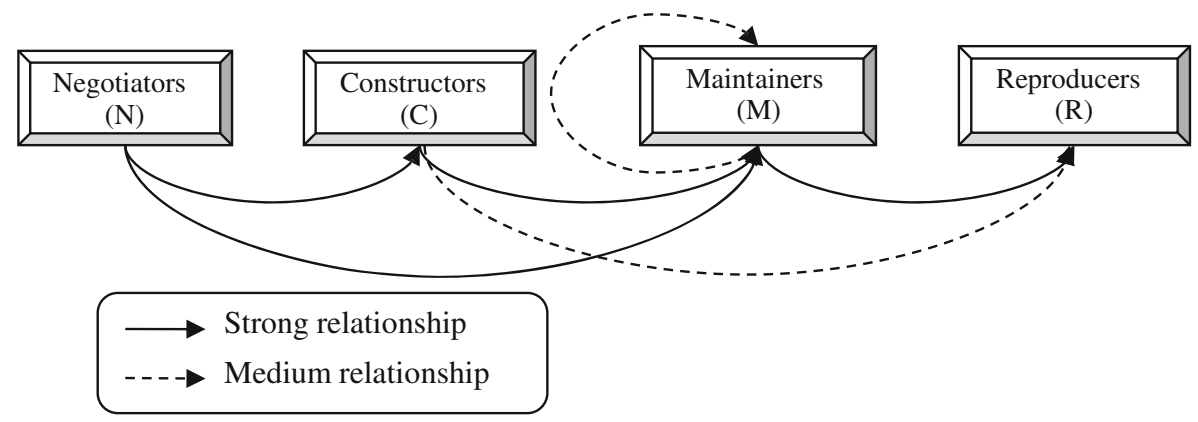

Fig. 2 Basic model of the vectoral flows of women seafarers' identity management shifts while at sea 
between identity management groups are marked as solid arrows, and the medium relationships are marked as dotted arrows. The weak relationships are not shown in Fig. 1. Based on the analysis of the significance of such vectoral information, a general tendency of women seafarers' shipboard identity management can be characterised as a flow of negotiators $\rightarrow$ constructors $\rightarrow$ maintainers $\rightarrow$ reproducers $(\mathrm{N} \rightarrow \mathrm{C} \rightarrow \mathrm{M} \rightarrow \mathrm{R})$. This pattern demonstrates the chronological order of women seafarers' identity management and visualises the process of women's changing strategies over time.

\section{Conclusion}

The research found that many women seafarers on cargo ships experienced genderrelated problems including sexual harassment by their male colleagues, as it is similarly observed in the cases of women in other sectors such as firefighters (Yoder and Aniakudo 1995, 1996), army officers (Pettersson et al. 2008), police (Holdaway and Parker 1998) and the navy (Newell et al. 1995). According to the interviews with women seafarers, their gender-related problems were brought about by the working environment which reflects the occupational culture embracing masculine norms and values. In order to fit into such a male-oriented culture on board ships, women seafarers learned by themselves and invented various identity management strategies. While the study of Cassell and Walsh (1993) explained gender management in a broader sense, this research contributed to the development of the typologies of such gender identity management strategies which women seafarers utilised to solve their problems while at sea.

This research categorised those strategies according to four distinguished identity management groups: negotiators, constructors, maintainers and reproducers. Each group includes a few identity management strategies, such as the obscurers of femininity. Many women began with a negotiator strategy when they started working on board and realised that they need to adjust to the work and living environment of a ship. Some further developed their identity management and applied a constructor strategy. Most women seafarers experienced a maintainer strategy which seemed to be the most stable and balanced in their state of mind. By contrast, reproducer strategies were utilised by less women in my sample, and it seems to take a long process to reach the reproducer group of identity management.

Except for two never-changed women seafarers, the majority of women in my sample (34/36) changed their identity management strategies over time while at sea. Although the interview data suggest that women are diverse and their identity management patterns vary, the research identified a typical shifting flow of their identity management on board ships as $\mathrm{N} \rightarrow \mathrm{C} \rightarrow \mathrm{M} \rightarrow \mathrm{R}$. This identity management model of women seafarers while at sea will help us understand the process of their struggles when working on board ships. The shipping companies may be able to design a plan of employment support for women seafarers if they foresee possible difficulties of their female employees. For example, the manning section of a company can launch a hotline to provide assistance to their women seafarers when they encounter gender-related problems while at sea. It is also important to advise women seafarers that most gender-related issues they may experience on board should not be taken personally and that they should not blame themselves for being 
in the 'wrong' place. A better understanding of the seafaring culture is crucial for both male and female seafarers as well as for shipowners and managers of manning agencies. Social and cultural aspects of seafaring occupations could have an impact on seafarers' lives at sea, and thus, it cannot be underestimated.

Acknowledgments I gratefully acknowledge the support of Nippon Foundation as well as all the participants who shared their experiences to accomplish this research project.

\section{References}

Belcher P et al (2003) Women seafarers: global employment policies and practices. International Labour Organization (ILO), Geneva

BIMCO/ISF (2010) BIMCO/ISF manpower update, 2010: the worldwide demand for and supply of seafarers: main report. Coventry, University of Warwick Institute of Employment Research

Brickman JP (2012) Recruitment and retention of women in the maritime industry. In: The 13th Annual General Assembly of the IAMU, St. John's, Canada, 15-17 October 2012. pp 193-205

Cassell C, Walsh S (1993) Being seen but not heard: barriers to women's equality in the workplace. Psychologist 6:110-114

DeSimone R (2010) Technology removes romance from time-honoured profession. Lloyd's List, 02 November

Holdaway S, Parker SK (1998) Policing women police: uniform patrol, promotion and representation in the CID. Br J Criminol 38(1):40-60

ILO (2005) Governing body 294th session. ILO, Geneva

Kvale S (1996) InterViews: an introduction to qualitative research interviewing. Thousand Oaks, Sage

Maynard M, Purvis J (eds) (1994) Researching women's lives from a feminist perspective. Taylor \& Francis, London

Nautilus (2012) Telegraph. 45 (1-12). London, Nautilus International

Newell CE, Rosenfeld P, Culbertson AL (1995) Sexual harassment experiences and equal opportunity perceptions of navy women. Sex Roles 32(3/4):159-168

Pettersson L et al (2008) Changing gender relations: women officers' experiences in the Swedish armed forces. Econ Ind Democr 29(2):192-216

Sulpice G (2011) Study on EU seafarers employment: final report. European Commission, DirectorateGeneral for Mobility and Transport, Directorate C - Maritime Transport

Weber M (1949) Objectivity in social science and social policy. In: Shils EA, Finch HA (eds) The methodology of the social sciences. Free Press, New York

Yoder JD, Aniakudo P (1995) The responses of African American women firefighters to gender harassment at work. Sex Roles 32(3-4):125-137

Yoder JD, Aniakudo P (1996) When pranks become harassment: the case of African American women firefighters. Sex Roles 35(5-6):253-270 